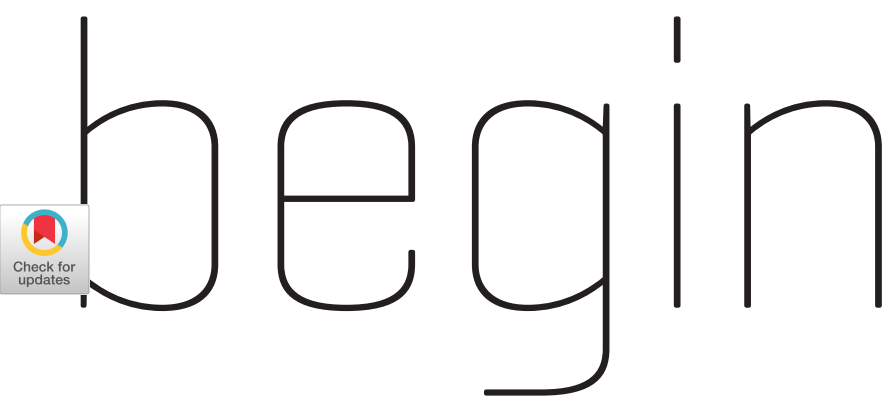

\section{Global Cultures and Computing}

C ulture is hidden in the way we communicate. It's hidden in the way we carry ourselves. It's hidden in the myriad of interactions that are scattered throughout our everyday, especially in global fields such as computing, where our individuality is rooted in our beliefs and perspectives.

From tribal units to global social movements, we are inherently beholden to innate manifestations sown into our beings from ages past. In post-colonial societies, the notion of culture is complicated. Colonization has left a legacy that inflates tendencies toward westernized ideas and so-

\section{Ihope this issue of XRDS alerts you to the multi-faceted nature of technologies and the importance of understanding different cultural perspectives.}

lutions. There is often a tension between pre-colonization beliefs and postcolonization practices.

However technology is designed devoid of cultural restraints. Designed to help, enhance experiences, or solve problems, technology is mostly intended to work at the singular purpose for which it was intended. Technology's identity is rooted in the purpose for which it was created. That's it's fingerprint.

Unlike the human fingerprint that is unique to each individual on the planet, technology has a print that does not hold constant. Even though it is created with a specific purpose, it quietly evolves based on the cultural lens through which it is viewed and also applied. Its applications become a reflection of the ethos of its users in the context that it is situated.

To ground our conversation, we open with an article on epistemologies of culture and the decolonization of design. Dr. Ahmed Ansari, Assistant Professor at New York University, uses Victor Papanek's seminal writings in Design for the Real World to structure his call for a collective understanding of how beliefs and perceptions frame people's everyday lived experiences, and how design research can benefit from such a stance.

We then present five articles showcasing technology application and design that have been influenced by culture, instances where consideration of unique cultural perspectives may improve technology. Dr. Michaelanne Dye, Presidential Postdoctoral Fellow at the University of Michigan, tells of the birth, maintenance, and repair of a neighborhood gaming meetup that grew into an informal community network as an alternative to the internet in Havana, Cuba. Deeply embedded in these stories is the resolver ethos-a cultural identity that describes how Cuban people work together to invent and persist despite hardships. It is an identity that is worn with pride.

Ph.D. students Cynthia Habonimana and Moses Namara from California State University and Clemson University respectively draw parallels between the design of traditional homestead (i.e. to promote community) and the prolific use of WhatsApp among certain communities (i.e. specifically, groups being seen as an extension of the physical homestead). In addition to this, they discuss the tension that exists be- tween histories rich with evidence of technological use and post-colonial attitudes toward invention and appropriation.

Another Ph.D. student, Elizabeth Resor from UC Berkeley, writes about how conventional approaches to mapping are rendered useless when users opt to intentionally keep their location data turned off. With an interest in mapping accident locations, Resor investigated how users were still able to share traffic location information using social media despite inactive GPS sensors.

Integrated with the legacy left by colonization, Naveena Karusala, a Ph.D. student at the University of Washington, explores the contextualized use of language in multilingual societies. She writes about the values related to language that are revealed in how these societies use technologies or make decisions to code switch. For example, the value of the use and knowledge of English being an indicator of status and privilege.

We close off this section with an account of designing in the face of cultural obstacles. In patriarchal societies, women are sometimes forced to endure harassment in silence. These cultures have the unfortu- 


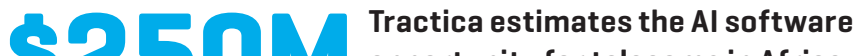 opportunity for telecoms in Africa will be more than $\$ 250$ million by 2025 .}

nate side effect of ostracizing those who speak out. Dr. Nova Ahmed, Associate Professor at North South University, shares her experience in attempting to break the silence and empower those affected using an IOT solution. Triggered by a public humiliation that forced a young school girl (a victim of harassment) to take her own life, Ahmed and her collaborators sought to answer the question: "How do you design a solution that helps a group of people who have only known silence as their defense mechanism?"

Also in this issue are articles that offer critiques of present-day standards (i.e. policy and frameworks); the

From tribal
units to
global social
movements,
we are
inherently
beholden
to innate
manifestations
sown into
our beings
from ages past.

authors here speculate on how current standards can be enriched and influenced by different cultural perspectives. Ezinne Nwankwo, a Ph.D. student at Duke University, and Belona Sonna, a graduate student at the African Institute for Mathematical Sciences, explores the missing elements of an AI ethical framework and the need for more diverse perspectives. Nwankwo and Sonna specifically draw elements from social contracts that have long been discussed by African philosophers.

As AI becomes more prevalent in technology and solutions, Micheal Nayebare, a software engineer, writes about the need to take into account evolving cultures to ensure these policies have an impact. He explores and discusses five key areas that African countries should consider when drafting AI policy guidelines. Finally, no discussion is truly complete without considering cybersecurity.

Hood Mukiibi, a security engineer, unpacks the state, or lack thereof, of cybersecurity within the African context. Exploring the nature of breaches in different countries, he makes the argument for the need of context specific security policies.

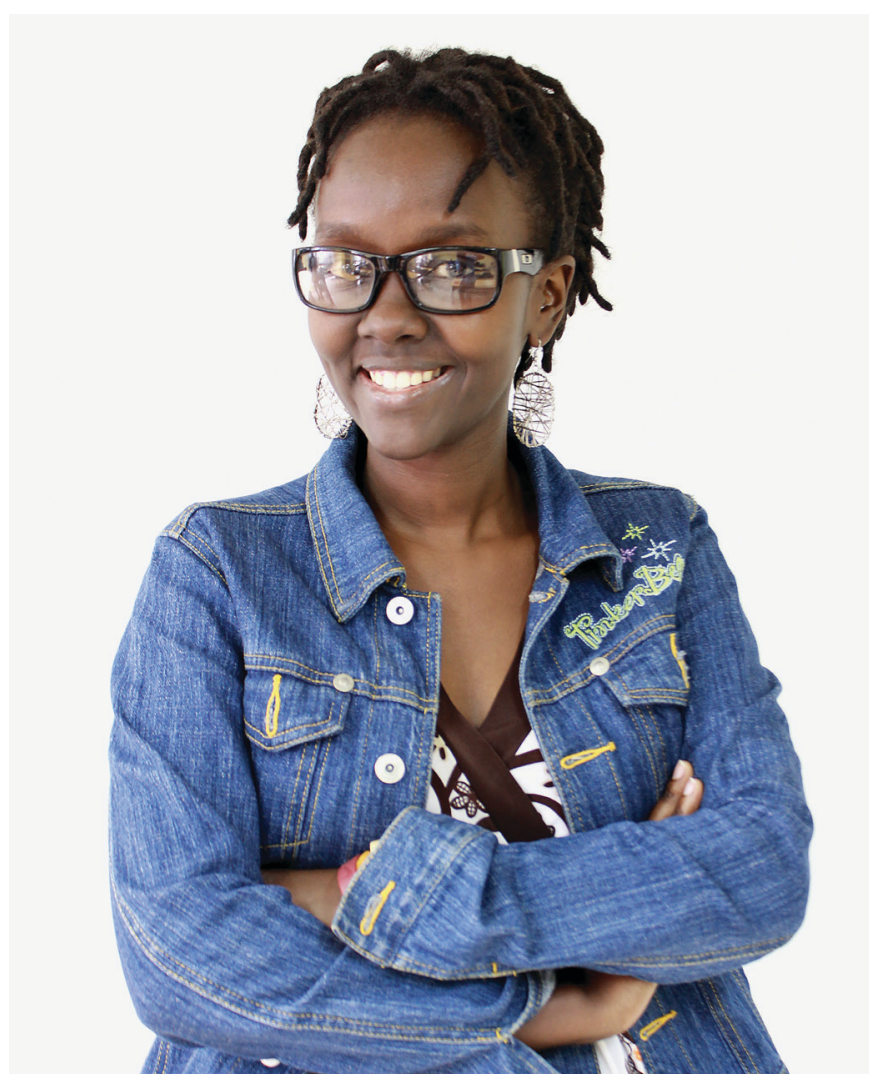

Last, is a personal perspective on bringing culture to the application and design of technology. Joreen Arigye, a recent Carnegie Mellon University Africa alumnus, shares her journey from software engineer to data analyst. She also discusses how she has seen culture (both intrinsic and organization) influence the work that she does.

To conclude, these 10 articles are an invitation for you to take a critical glance at the everyday experiences that exist around you. Whether you are a researcher, designer, or consumer of technologies, I hope this issue of $X R D S$ alerts you to the multi-faceted nature of technologies and the importance of understanding different cultural perspectives.

-Lynn Kirabo, Guest Editor Copyright held by author.
DOI: $10.1145 / 3368038$ 